\title{
Folate receptor-targeted molecular imaging improves identification of malignancy during pulmonary resection: a case report
}

\author{
Jarrod D. Predina ${ }^{1,2^{*}}$, Andrew Newton ${ }^{1,3}$, Courtney Connolly $y^{1,3}$ and Sunil Singhal ${ }^{1,2^{*}}$
}

\begin{abstract}
Background: During minimally invasive pulmonary resection, both limited visualization and tactile feedback can make localization of pulmonary nodules and assessment for synchronous disease challenging. Intraoperative molecular imaging is an emerging technology that can enhance a surgeon's ability to detect cancers at the time of resection.

Case presentation: In this report, we describe the application of a folate receptor-targeted, near infrared optical contrast agent (OTL38) for the detection of an invasive pulmonary adenocarcinoma. During molecular imaging, an otherwise undetectable synchronous nodule was also identified. This finding resulted in intraoperative upstaging and operative plan modifications.

Conclusion: This report marks the first successful utilization of a targeted, near infrared intraoperative molecular imaging probe useful for thoracic malignancies. This rapidly evolving technology may enhance the surgeon's ability to perform a number of oncologic procedures including tumor localization, margin assessment and intraoperative staging.
\end{abstract}

Keywords: Pulmonary adenocarcinoma, Surgery, Intraoperative imaging, Folate receptor alpha

\section{Background}

During minimally invasive pulmonary resection, both limited visualization and tactile feedback can make localization of pulmonary nodules and synchronous disease challenging. Current techniques to improve intraoperative detection include intraoperative ultrasound, radionucleotide imaging, and CT-guided or spiral wire localization [1]. There are, however, challenges associated with these approaches, such as the requirement of prior knowledge regarding nodule location and the potential for patient morbidity [1]. Several groups have proposed utilization of targeted, near-infrared (NIR) fluorescent contrast agents for real-time intraoperative cancer detection; however, this has not been successfully executed for thoracic neoplasms [2]. In this report, we describe the first human experience utilizing targeted, NIR intraoperative imaging with the folate receptor alpha (FR $\alpha)$ targeted optical contrast agent (OTL38) to localize known pulmonary nodules and identify synchronous disease.

\footnotetext{
*Correspondence: jpredina@partners.org; sunil.singhal@uphs.upenn.edu ${ }^{1}$ Center for Precision Surgery, Perelman School of Medicine at the University of Pennsylvania, Philadelphia, USA

Full list of author information is available at the end of the article
}

\section{Case Presentation}

A 72-year-old female with a 60-pack-year smoking history presented with an incidentally identified $2.3 \mathrm{~cm}$ solitary pulmonary nodule of the left upper lobe. Preoperative PET-CT confirmed FDG uptake, no suspicious lymphadenopathy or additional pulmonary pathology was observed (Fig. 1a, b). Four hours prior to tumor resection, OTL38 $(0.025 \mathrm{mg} / \mathrm{kg})$ was delivered intravenously. At the time of surgery, the preoperatively identified left upper lobe nodule displayed high levels of fluorescence (Fig. 2a, b). In addition to the known left upper lobe nodule, an additional suspicious area of fluorescence was noted in the left lower lobe (Fig. 2c, d, and Additional file 1: Video). This second area was not concerning on preoperative imaging and displayed no other obvious visual or palpable irregularities intraoperatively. The identified synchronous left lower lobe lesion was wedge resected using real-time fluorescence guidance. Frozen section analysis revealed a $0.4 \mathrm{~cm}$ invasive pulmonary adenocarcinoma, and final pathology confirmed folate receptor-alpha expression. Due to identification of this synchronous adenocarcinoma, the left upper lobe nodule wedge resected rather than removed by lobectomy as 


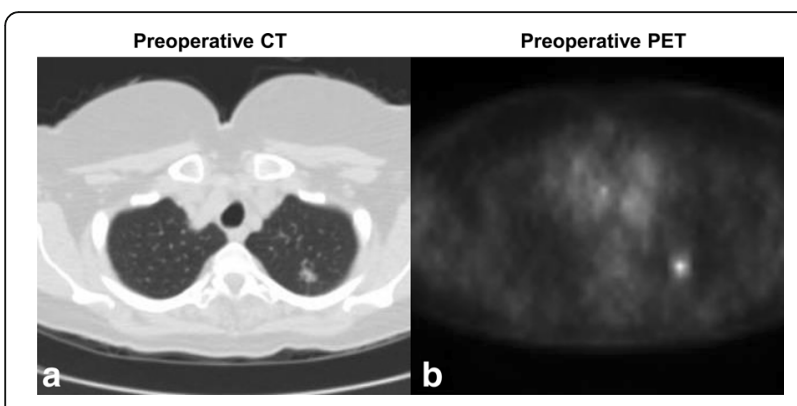

Fig. 1 Preoperative CT (a) and PET (b) revealing an FDG-avid nodule in the LUL

originally planned. In addition to intraoperative plan modification, identification of the occult left lower lobe adenocarcinoma upstaged the disease and the subject thus received systemic platinum-based chemotherapy following resection. After one year of follow-up, the patient has had no evidence of disease recurrence or drug toxicity.

\section{Discussion}

Intraoperative molecular imaging, also commonly referred to as fluorescence guided surgery, is a rapidly evolving technique that can enhance the surgeon's ability to perform a number of intraoperative tasks including nodule localization, metastasis evaluation, and margin assessment. In this report, we demonstrate utility of
NIR molecular imaging using the FR $\alpha$-targeted contrast agent, OTL38.

OTL38 (chemical formula: $\mathrm{C}_{61} \mathrm{H}_{63} \mathrm{~N}_{9} \mathrm{Na}_{4} \mathrm{O}_{17} \mathrm{~S}_{4}$ (Tetrasodium salt); molecular weight: $1414.42 \mathrm{Da}$ ) is a folate analogue conjugated to the NIR fluorescent dye, S0456 [3] The FR $\alpha$ is an attractive target given known expression in many malignancies, including pulmonary adenocarcinomas [4]. OTL38 exploits highly specific FR $\alpha$-targeted binding which has similarly observed with the visual contrast agent, EC17 (folate-FITC) [5]. Unlike EC17, folate is linked to a NIR fluorophore in OTL38 and emits in the NIR range $\left(\lambda_{\text {ex }} 774\right.$ and $\left.\lambda_{\text {em }} 795\right)$ [6]. NIR imaging probes have several advantages over visual range probes; most notably, less autofluorescence and superior depth of penetration.

This report highlights several important lessons involving molecular imaging with OTL38. First, we found molecular imaging with OTL38 feasible. To elaborate, OTL38 delivery occurs 3-6 h prior to resection and imaging, thus can be delivered in the preoperative holding area. Alternative agents are delivered days prior to resection [2]. Further, using a commercially available imaging system capable of NIR detection (Iridium, Visionsense, Philadelphia, PA, USA), we found that implementation of molecular imaging only added a few minutes to the case duration. Second, we found delivery of OTL38 to be safe, with no toxicity being observed. This low toxicity profile is in accordance with the data involving other

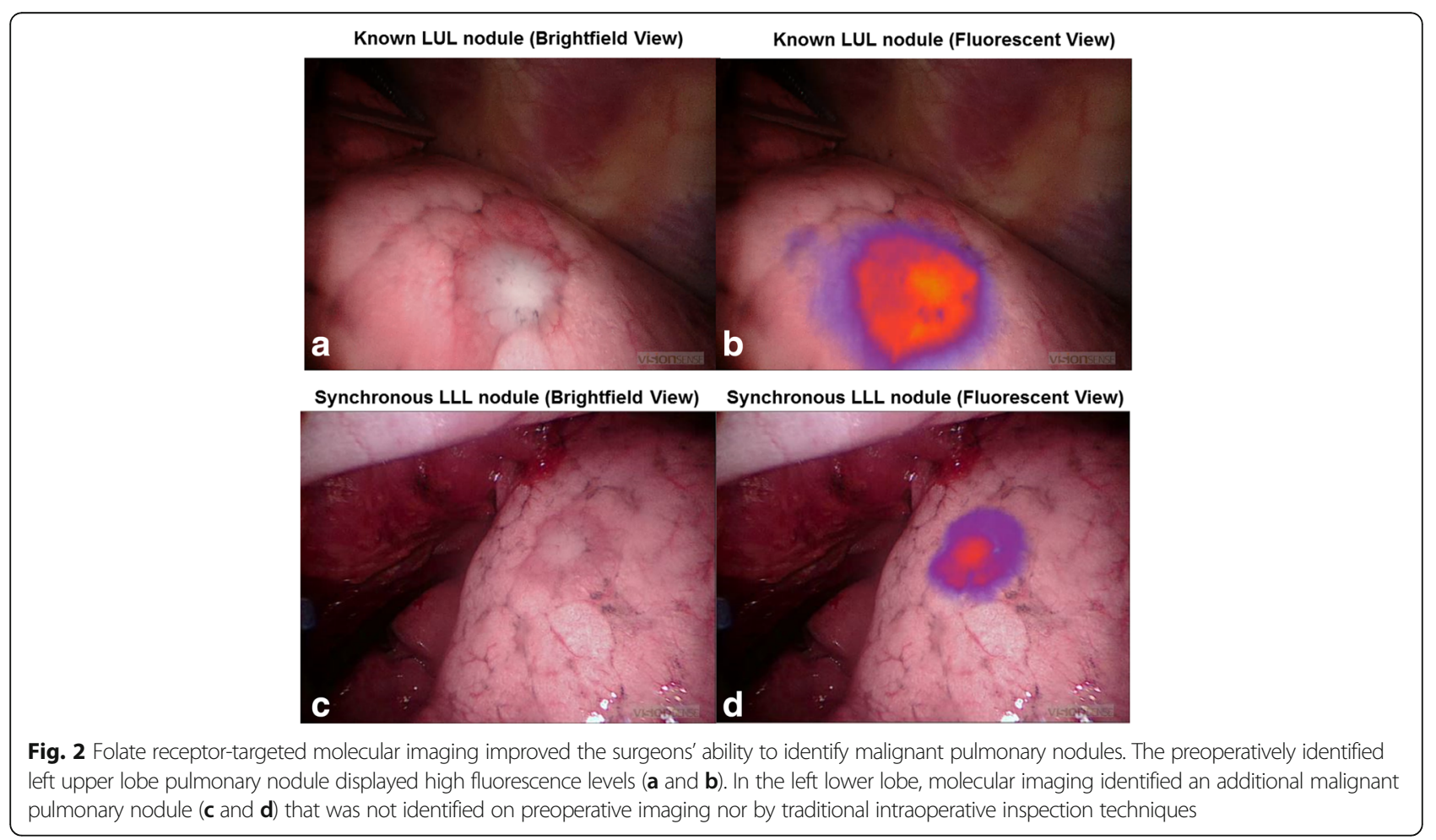


targeted intraoperative optical contrast agents currently under investigation $[2,6]$. Finally, OTL38 allowed the operating surgeon to identify a synchronous subcentimeter pulmonary adenocarcinoma which would otherwise have been missed. This subcentimeter sensitivity provides data suggesting that this technology may ultimately enhance oncologic resections by identification of positive/close resection margins or small synchronous cancer foci that are not detected preoperatively or intraoperatively. At this point, we are further evaluating this technology in a Phase I clinical trial (NCT02602119).

\section{Conclusion}

This report marks the first successful utilization of a targeted, near infrared intraoperative molecular imaging probe useful for thoracic malignancies. In the future, this technology may enhance the surgeon's ability to perform a variety of oncologic procedures including tumor localization, margin assessment and intraoperative staging.

\section{Additional file}

Additional file 1: Intraoperative molecular imaging allowed for identification of an additional malignant pulmonary nodule in the left lower lobe. Identification of this synchronous malignancy upstaged the patient, modified operative planning, and altered postoperative adjuvant course. (MP4 $49087 \mathrm{~kb})$

\section{Abbreviations}

CT: Computed tomography; FR: Folate receptor; IMI: Intraoperative molecular imaging; NIR: Near infrared; PET: Positron emission tomography

\section{Acknowledgements}

We would like to thank On Target Laboratories (West Lafayette, IN, USA) for providing OTL38 to us free of cost.

\section{Funding}

JDP was supported by a grant from the American Philosophical Society, the $\mathrm{NIH}$ (F32 CA210409) and the Association for Academic Surgery Research Grant. SS was supported by the NIH (R01 CA193556).

\section{Data sharing}

Data sharing not applicable to this article as no datasets were generated or analyzed during the current study.

\section{Authors' contributions}

JDP and SS took care of the described patient. JDP, AN, CC, and SS obtained data, analyzed data and wrote the manuscript. All authors read and approved the final manuscript.

\section{Ethics approval and consent to participate}

The described patient provided consent to participate this study which was approved by the University of Pennsylvania Institutional Review Board.

\section{Consent for publication}

Written informed consent was obtained from the patient for publication of this case report and any accompanying images. A copy of the written consent is available for review by the Editor-in-Chief of this journal.

\section{Competing interests}

The authors declare that they have no competing interests.

\section{Publisher's Note}

Springer Nature remains neutral with regard to jurisdictional claims in published maps and institutional affiliations.

\section{Author details}

${ }^{1}$ Center for Precision Surgery, Perelman School of Medicine at the University of Pennsylvania, Philadelphia, USA. ${ }^{2}$ Division of Thoracic Surgery, Department of Surgery, Perelman School of Medicine at the University of Pennsylvania, 6 White building; 3400 Spruce St, Philadelphia PA 19104, USA. ${ }^{3}$ Department of Surgery, Perelman School of Medicine at the University of Pennsylvania, Philadelphia, USA.

Received: 29 June 2017 Accepted: 15 November 2017 Published online: 04 December 2017

References

1. Keating J, Singhal S. Novel methods of Intraoperative localization and margin assessment of pulmonary nodules. Semin Thorac Cardiovasc Surg. 2016;28(1):127-36.

2. Rosenthal EL, et al. Safety and tumor specificity of Cetuximab-IRDye800 for surgical navigation in head and neck cancer. Clin Cancer Res. 2015;21(16): 3658-66.

3. van Dam GM, et al. Intraoperative tumor-specific fluorescence imaging in ovarian cancer by folate receptor-alpha targeting: first in-human results. Nat Med. 2011;17(10):1315-9.

4. O'Shannessy DJ, et al. Folate receptor alpha expression in lung cancer: diagnostic and prognostic significance. Oncotarget. 2012;3(4):414-25.

5. Kennedy GT, et al. The optical biopsy: a novel technique for rapid Intraoperative diagnosis of primary pulmonary Adenocarcinomas. Ann Surg. 2015;262(4):602-9.

6. Hoogstins $C E$, et al. A novel tumor-specific agent for Intraoperative near-infrared fluorescence imaging: a translational study in healthy volunteers and patients with ovarian cancer. Clin Cancer Res. 2016;22(12):2929-38.
Submit your next manuscript to BioMed Central and we will help you at every step:

- We accept pre-submission inquiries

- Our selector tool helps you to find the most relevant journal

- We provide round the clock customer support

- Convenient online submission

- Thorough peer review

- Inclusion in PubMed and all major indexing services

- Maximum visibility for your research

Submit your manuscript at www.biomedcentral.com/submit
C Biomed Central 